\title{
SERVICE INNOVATION PADA HOTEL SANTIKA MATARAM
}

\section{Muhammad Rahmatul Burhan ${ }^{1}$, Muhammad Ali ${ }^{2}$}

1Program Studi Administrasi Publik, Universitas Muhammadiyah Mataram, Indonesia

Email: ramaehrama@gmail.com

2 Program Studi Administrasi Publik, Universitas Muhammadiyah Mataram, Indonesia.

E-mail: khaidiraliihsan@gmail.com

\begin{tabular}{|c|c|}
\hline ARTICLE INFO & ABSTRACT \\
\hline Keywords: & A changing and hyper competitive market environment is \\
\hline Hotel; Service Innovation; Marketing; & necessary for hotel companies to provide superior services \\
\hline Technology & $\begin{array}{l}\text { needed by consumers. This study aims to determine service } \\
\text { innovations at the Santika Hotel Mataram. This research was }\end{array}$ \\
\hline Kata Kunci: & designed using a qualitative approach.. After being analyzed \\
\hline $\begin{array}{l}\text { Hotel; Inovasi Layanan; Pemasaran; } \\
\text { Teknologi }\end{array}$ & $\begin{array}{l}\text { using the Interactive Model, the results of the study showed } \\
\text { that four dimensions of service innovation had been applied by } \\
\text { the Hotel Santika Mataram. Technology plays an important }\end{array}$ \\
\hline $\begin{array}{l}\text { How to cite: } \\
\text { Burhan, M. R., Ali, Muhammad.,(2020). } \\
\text { Analisis Service Innovation Pada Hotel }\end{array}$ & $\begin{array}{l}\text { role as a facilitator in the application of service innovations at } \\
\text { Hotel Santika Mataram. }\end{array}$ \\
\hline $\begin{array}{l}\text { Santika Mataram. 9(3), 220-229 } \\
\text { DOI: } \\
\text { http://dx.doi.org/10.29303/jmm.v9i3.557 }\end{array}$ & $\begin{array}{l}\text { Lingkungan pasar yang terus berubah dan hyper } \\
\text { competitive menuntut perusahaan hotel perlu memberikan } \\
\text { layanan superior yang dibutuhkan oleh konsumen. }\end{array}$ \\
\hline & Penelitian ini bertujuan untuk mengetahui inovasi \\
\hline $\begin{array}{ll}\text { Dikumpulkan } & : 21 \text { Juli } 2020 \\
\text { Direvisi } & \text { :28 Juli } 2020\end{array}$ & layanan di Hotel Santika Mataram. Penelitian ini \\
\hline Dipublikasi : 26 Agustus 2020 & $\begin{array}{l}\text { dianalisis menggunakan Interactive Model, hasil penelitian } \\
\text { menunjukkan bahwa empat dimensi inovasi layanan } \\
\text { telah diterapkan oleh Hotel Santika Mataram. Teknologi } \\
\text { berperan penting sebagai fasilitator dalam penerapan } \\
\text { inovasi layanan yang ada di Hotel Santika Mataram. }\end{array}$ \\
\hline & $\begin{array}{l}\text { Copyright @ 2020. Muhammad Rahmatul Burhan, } \\
\text { Muhammad Ali. JMM UNRAM. All rights } \\
\text { reserved. }\end{array}$ \\
\hline
\end{tabular}




\section{PENDAHULUAN}

Hotel Santika Mataram merupakan salah satu hotel berbintang di Kota Mataram yang memiliki citra baik di mata konsumennya. Bisa dikatakan hotel ini tidak pernah sepi. Hotel Santika Mataram berdiri pada tahun 2012, yang saat itu di Kota Mataram hanya ada tiga hotel yang menyasar target pasar yang sama dengan Hotel Santika Mataram. Hotelhotel tersebut antara lain Lombok Raya yang sudah menjadi ikon kota mataram sejak tahun 1994, diikuti oleh Grand Legi (dahulunya Sahid Legi) yang berdiri tahun 1997, dan Lombok Garden yang beroperasi mulai tahun 2007. Perkembangan dunia pariwisata membawa dampak besar di Kota Mataram karena meningkatnya angka kunjungan wisatawan di Lombok. Sehingga berdirilah hotel-hotel baru seperti Lombok Plaza yang beroperasi hampir bersamaan dengan Hotel Santika Mataram, lalu Golden Palace tahun 2014, Golden Tulip tahun 2015 (berganti nama menjadi Lombok Astoria tahun 2017), Fave Hotel tahun 2015, dan Aston Inn tahun 2016.

Munculnya berbagai hotel-hotel tersebut tentu meningkatkan persaingan Hotel Santika Mataram dalam menarik konsumennya. Hotel Santika Mataram harus meningkatkan kemampuan perusahaannya agar tetap bersaing, salah satu caranya adalah melakukan inovasi jasanya (service innovation) karena menurut Rahayu, Syairudin, \& Pertiwi (2015), kemampuan inovasi akan mempengaruhi kinerja perusahaan. Pentingnya service innovation terutama karena lingkungan pasar yang tidak bisa diprediksi dan cepat berubah atau hyper competitive, sehingga pelanggan menjadi lebih penuntut karena adanya variasi penawaran dari organisasi-organisasi yang berkompetisi dalam industri yang sama (Victorino, Verma, Plaschka, \& Dev, 2005 dalam Lemy, 2010). Service innovation menjadi salah satu jawaban untuk merespon perubahan lingkungan tersebut (Kandampully \& Duddy, 1999 dalam Nanggong, 2013). Alasan lain pentingnya service innovation oleh Hotel Santika Mataram adalah untuk meningkatkan kepuasan pelanggan dan kinerja perusahaan secara efektif. Penerapan service innovation dalam bisnis hotel terbukti meningkatkan nilai pelanggan sehingga mendapatkan pengakuan dan kepuasan pelanggan bahkan meningkatkan frekuensi pembelian kembali oleh pelanggan.(Weng, Ha, Wang, Tsai, 2012).

Pada sisi lain, para ahli mengatakan penelitian mengenai service innovation atau dalam sektor jasa masih relatif sedikit dilakukan (Leich, Gokduman, \& Baaken, 2010). Diskusi tentang inovasi di sektor jasa jarang diartikulasikan dalam studi inovasi. Hal ini lebih sering ditemui dalam studi budaya, dan bahkan kemudian sering tidak digambarkan sebagai inovasi. Penelitian inovasi selama ini didominasi oleh perusahaan manufaktur (Gellatly \& Peters, 1999; Harmon, 2012). Ini termasuk alasan mengapa penelitian dianggap penting dilakukan pada perusahaan jasa yang diharapkan menjadi sumber yang inovatif untuk waktu yang lama, karena berdasarkan studi menunjukkan bahwa banyak perusahaan jasa dan industri jasa sebenarnya sangat inovatif (Leich, Gokduman, \& Baaken, 2010).

Oleh karena itu, penelitian ini bertujuan untuk mengetahui service innovation yang dilakukan dalam lingkungan Hotel Santika Mataram. Hasil dari penelitian ini agar menjadi tambahan ilmu bagi peneliti dan juga diharapkan mampu menjadi acuan maupun referensi bagi perusahaan khususnya perhotelan untuk mengembangkan inovasi pada pelayanan, sehingga dunia pariwisata semakin maju khususnya di Pulau Lombok. 


\section{Jurnal Magister Manajemen Unram Vol. 9, No 3. September 2020 NATIONALIY ACCREDITED JOURNAL - DECREE NO. 21/E/KPT/2018}

\section{TINJAUAN PUSTAKA}

\subsection{Penelitian Terdahulu}

Beberapa penelitian yang relevan dengan penelitian ini berhasil peneliti kumpulkan. Penelitian tentang inovasi pada jasa menggambarkan pentingnya melakukan inovasi. Lemy (2010), dalam penelitiannya yang mengidentifikasi indikator inovasi jasa yang mempengaruhi preferensi pelanggan dalam memilih hotel menyatakan permasalahan-permasalahan yang timbul dalam hal kualitas jasa seringkali disebabkan oleh kesalahan inovasi jasa yang dilakukan oleh perusahaan. Hal itu berimbas terhadap keunggulan kompetitif perusahaan jasa yang dapat dengan mudah diimitasi oleh kompetitor.

Hasil itu menggambarkan jasa-jasa yang baru dikembangkan tidak dirancang secara benar, sehingga sering terjadi kesalahan dalam proses penyampaian jasa tersebut kepada pelanggan. Hotel yang dapat mengakomodir permintaan konsumen secara optimal akan menjadi hotel yang banyak dipilih oleh konsumen

Penelitian oleh Weng, Ha, Wang, Tsai (2012), yang meneliti hubungan antara service innovation dengan kepuasan pelanggan pada industri perhotelan di Taiwan memberikan pembuktian dalam penelitiannya bahwa pelaku bisnis hotel yang dapat memanfaatkan kemampuannya dalam menerapkan inovasi jasa untuk meningkatkan nilai pelanggan akan mendapatkan pengakuan dan kepuasan pelanggan bahkan meningkatkan frekuensi pembelian kembali oleh pelanggan.

Konsep lain mengenai pentingnya inovasi memaparkan bahwa inovasi jasa menjadi salah satu jawaban untuk merespon perubahan lingkungan yang cepat atau hyper competitive. Inovasi jasa dibutuhkan untuk memahami sifat kebutuhan konsumen yang kompleks dan nilai yang dikaitkan pada produk atau jasa tersebut (Kandampully and Duddy, 1999 dalam Nanggong, 2013). Proses produksi jasa bertumpu pada skill dan pengetahuan penyedianya, proses inovasi jasa dalam perusahaan berbasis pada relasional. Karena ide, pengetahuan, dan skill dalam berinovasi tidak berasal dari internal perusahaan saja tetapi juga berasal dari luar perusahaan, seperti pelanggan, pemasok bahkan dari pesaing itu sendiri. Dalam aspek relasional ini terdapat pertukaran yang akan mengakibatkan keunggulan kompetitif karena sharing knowledge terjadi dalam proses tersebut (Nanggong, 2013).

Penelitian yang relevan lainnya oleh Maruli \& Ali, (2013), penelitian ini dilakukan pada industri kerajinan batik Surakarta, juga menyatakan penyebab mengapa penerapan service innovation sangat dianjurkan dalam menghadapi pasar karena inovasi jasa mampu meningkatkan daya saing sebuah perusahaan, bahkan produk jasa yang diciptakan karena bila merujuk pada konsepnya, perusahaan akan mampu meluaskan wilayah pemasarannya sampai ke luar negeri. Hal itu karena inovasi-inovasi bukan hanya berasal dari pelaku usaha itu sendiri, tetapi juga rekanan bisnis, konsumen, pesaing dan lembaga riset/universitas.

Lebih lanjut, Hussain, Konar, \& Ali (2016) yang mengukur kinerja service innovation melalui perilaku sharing knowledge secara kuantitatif di Malaysia, membuktikan perilaku sharing knowledge dalam karyawan hotel memberikan efek positif pada proses inovasi jasa secara keseluruhan. Sedangkan bagi manajer, mereka harus fokus pada karyawan individu, mendorong dan memenuhi semua kebutuhan layanan mereka pasti akan menciptakan dampak positif dalam organisasi. Pengaruh dominan perilaku sharing knowledge terhadap proses inovasi jasa akan mengarah pada kepuasan pelanggan. 


\section{Jurnal Magister Manajemen Unram Vol. 9, No 3. September 2020 NATIONALIY ACCREDITED JOURNAL - DECREE NO. 21/E/KPT/2018}

Dikatakan bahwa dalam inovasi terdapat sharing knowledge dengan menjaga hubungan atau relasional, yang artinya masing-masing pihak saling memberikan informasi yang penting untuk inovasi. Pemerintah, masyarakat, dan pelaku bisnis, saling memberikan informasi untuk kemajuan bersama.

Dalam penelitian-penelitian tersebut jelas berbeda dari lokasi penelitian, bahkan tidak dicontohkan aplikasinya ke dalam suatu badan usaha tertentu. Sedangkan penelitian ini dilakukan kepada Hotel Santika Mataram.

\subsection{Tinjauan Teori}

Inovasi dalam bidang jasa sama pentingnya dengan perusahaan manufaktur. Tantangan utamanya adalah bahwa sebagian besar penawaran dan inovasi jasa mudah ditiru. Tetapi, perusahaan yang memperkenalkan inovasi secara teratur akan mendapatkan sukses keunggulan sementara atas pesaingnya. Service innovation membawa manfaat baru atau sistem pengiriman layanan baru. Service innovation dapat memberikan perbedaan yang signifikan, sulit untuk ditiru oleh pesaing, dan dapat mengaktifkan peluang bagi penciptaan nilai jangka panjang dengan pelanggan. Beberapa ahli juga menyatakan bahwa kualitas perusahaan jasa diuji pada setiap pelaksaan jasa. Jika personel jasa membosankan, tidak dapat menjawab pertanyaan sederhana, atau saling berkunjung ke personel lain sementara konsumen menunggu, konsumen akan berpikir dua kali untuk melakukan bisnis lagi dengan penjual jasa itu (Kotler dan Keller, 2009).

Inovasi di semua industri jasa terdapat karakteristik inti (Gellatly \& Peters, 1999):

a. Inovator dalam sektor jasa menekankan kebutuhan untuk mempertahankan atau meningkatkan pangsa pasar dengan berfokus pada pelanggan yang sudah ada dan meningkatkan kualitas produk. Penekanan pada strategi produk berfungsi untuk membedakan perusahaan jasa inovatif dari rekan-rekan mereka di bidang manufaktur, di mana strategi inovasi umumnya lebih menekankan pada metode produksi.

b. Pelanggan sering memainkan peran sentral dalam pengembangan inovasi. Dalam setiap industri jasa dipelajari, pelanggan merupakan sumber yang paling penting dari informasi untuk ide-ide inovatif. Mencerminkan fakta bahwa layanan dapat sangat dibedakan untuk memenuhi kebutuhan individual. Sebuah orientasi pelanggan yang kuat begitu juga dari pasar yang sangat kompetitif di mana pelanggan dapat segera berganti kepada perusahaan pesaing. Mengingat orientasi pelanggan yang kuat, tidak mengherankan bahwa peningkatan dalam beberapa aspek kualitas pelayanan mewakili manfaat utama dari inovasi dalam setiap industri jasa.

c. Inovator dalam industri jasa menekankan penggunaan hak cipta dan merek dagang atas instrumen kekayaan intelektual formal lainnya. Merek dagang sangat dibutuhkan karena pentingnya pengakuan merek di pasar di mana konsumen dapat dengan mudah beralih dari satu produsen ke yang lain, dan di mana kompetisi bergantung pada pengakuan produk dan loyalitas merek.

Karakteristik yang diuraikan di atas menunjukkan bahwa inovator sektor jasa dituntut memiliki profil yang umumnya konsisten yang berfokus pada kualitas, fleksibilitas untuk selera pelanggan yang beragam. Perusahaan jasa harus mengingat pentingnya interaksi pelanggan, spesialisasi produk dan fleksibilitas layanan untuk kegiatan inovasi mereka.

Dalam Harmon (2012), ada empat cara dalam menciptakan pelanggan dalam service innovation: 
a. Solusi yang fleksibel. Masalah pelanggan yang belum terpecahkan berubah menjadi peluang baru.

b. Kenyamanan yang terkendali. Perusahaan harus mencari cara untuk mengendalikan dan menempatkan pelanggan, kapan dan di mana mereka dapat dengan mudah mengakses layanan baru.

c. Menciptakan Keuntungan dengan Kenyamanan. Inovator perlu mengembangkan cara-cara kreatif untuk membuat pengalaman layanan yang lebih nyaman, khas, menyenangkan, dan mengesankan bagi pelanggan.

d. Menghormati Pelanggan. Dengan membuat lebih mudah bagi pelanggan untuk mengalami layanan dan menghormati kehadiran dan waktu mereka, inovator memiliki kesempatan lebih besar untuk menang.

Kegiatan inovasi dalam jasa juga cenderung menjadi proses yang berkesinambungan, yang terdiri dari serangkaian perubahan secara teratur dalam produksi dan proses. Ini kadang-kadang dapat mempersulit identifikasi inovasi dalam layanan dalam hal peristiwa tunggal, yaitu sebagai pelaksanaan perubahan signifikan dalam produksi, proses atau metode lainnya (Manual, 2005).

Service innovation merupakan fenomena multi dimensi. Sebuah layanan baru yang lengkap biasanya berarti pengenalan konsep layanan baru, saluran distribusi baru atau cara-cara berinteraksi dengan klien, sistem pengiriman layanan baru berupa rutinitas kerja baru, konsep organisasi baru, kebutuhan untuk teknologi baru atau paket perangkat lunak disesuaikan dan sebagainya. Model empat dimensi dalam service innovation diperkenalkan oleh Hertog (2010) yang menjadi kerangka kerja penelitian ini, yaitu:

\section{Gambar 2.1. Hertog's Framework of Service Innovation}

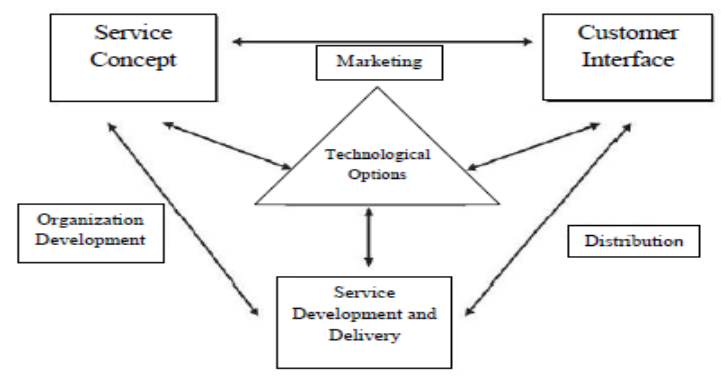

\section{a. Service Concept}

Produk yang diproduksi (dan proses) biasanya sangat nyata dan terlihat. Seperti ide baru atau konsep bagaimana mengatur solusi untuk masalah.

b. Customer Interface

Antarmuka ini adalah fokus dari service innovation yaitu tentang cara-cara baru berinteraksi dengan konsumen dan tentang integrasi mereka dengan saluran lain (multi-channeling).

c. Service Development and Delivery

Hal ini berkaitan erat dengan memberdayakan karyawan, untuk memfasilitasi mereka sehingga mereka dapat melakukan pekerjaan mereka dan memberikan layanan memadai. 


\section{Jurnal Magister Manajemen Unram Vol. 9, No 3. September 2020 NATIONALLY ACCREDITED JOURNAL - DECREE NO. 21/E/KPT/2018}

\section{d. Technological Option}

Teknologi sering dianggap sebagai enabler of service innovation. Banyak ahli yang mengakui implikasi yang mendalam dari teknologi terhadap layanan. Dalam banyak perusahaan besar/maju, ada proses yang sangat aktif dari perkembangan teknologi yang terjadi.

Intinya adalah bahwa service innovation dapat dicirikan oleh salah satu fitur yang dominan terkait dengan salah satu dimensi yang disebutkan di atas. Sangat mungkin fitur ini akan meminta satu set perubahan di dimensi lain, dalam rangka untuk mewujudkan inovasi yang sukses (Hertog, 2010).

\section{METODE PENELITIAN}

Penelitian ini mengadopsi pendekatan kualitatif yang bermaksud untuk memahami fenomena tentang apa yang dialami oleh subjek penelitian secara holistik dengan cara deskripsi dalam bentuk kata-kata dan bahasa pada suatu konteks khusus yang alamiah (Moleong, 2011:6). Untuk menjawab fokus penelitian, sebagai sumber data utama, peneliti mewawancarai dua orang informan kunci yaitu dari pihak Hotel Santika Mataram. Pihak dari Hotel Santika Mataram yaitu General Manager dan Manager Of Front Office Departement karena departemen ini yang secara langsung berhadapan dengan konsumen bahkan tempat konsumen mengeluarkan kritikan maupun saran.

Data utama yang didapat dari wawancara, disandingkan dengan data pendukung dari hasil observasi dan dokumentasi. Kemudian melewati tahap dua jenis metode triangulasi, yaitu triangulasi data dan triangulasi metodologis untuk mendukung analisis data secara Interactive Model dalam rangka penarikan kesimpulan.

\section{HASIL PENELITIAN DAN PEMBAHASAN}

\subsection{Service Innovation pada Hotel Santika}

Dalam bidang pariwisata di Lombok di mana Hotel Santika Mataram tergabung di dalamnya, Hotel Santika Mataram secara tidak langsung mempengaruhi nama Lombok untuk masa yang akan datang di mata wisatawan sebagai penyedia jasa. Untuk itu, Hotel Santika Mataram harus tanggap terhadap perubahan lingkungan pasar yang cepat berubah. Peneliti telah berhasil mengidentifikasi service innovation oleh Hotel Santika Mataram sebagai salah satu perusahaan jasa yang ada di Lombok;

a. Service Concept

Hotel Santika Mataram memiliki konsep minimalis dari segi desain di tiap ruangannya, konsep minimalis dianggap modern dan efisien biaya. Selain itu, minimalis juga dari segi efisiensi energi. Hotel Santika Mataram menerapkan hemat energi seperti contoh pada restorannya dengan mematikan pendingin ruangan saat ruangan tidak dipakai oleh konsumen. Service concept yang lain pada Hotel Santika Mataram adalah Hotel Santika Mataram mengusung tema "Indonesian Home" di mana menyediakan mayoritas menu makanan lokal asli Indonesia. Yang menjadi andalan di restoran Hotel Santika Mataram adalah menu Tengkleng Kambing. Hotel Santika Mataram berinovasi memanfaatkan hasil bumi Lombok untuk membuat "Tortilla" dari ubi ungu. Hotel Santika Mataram memanfaatkan petani ubi yang ada di Lombok untuk menyuplai hasil panennya. Kemudian salah satu yang menonjol dari Hotel Santika Mataram adalah pihak hotel melakukan 


\section{Jurnal Magister Manajemen Unram Vol. 9, No 3. September 2020 NATIONALIY ACCREDITED JOURNAL - DECREE NO. 21/E/KPT/2018}

kerjasama untuk memberikan harga dan diskon spesial bagi konsumen dari hotel-hotel yang ada di Gili MATRA (Meno, Air, Trawangan).

b. Customer Interface

Hotel Santika Mataram menerapkan moto "Hospitality From The Heart" dalam melayani konsumennya. Karyawan di hotel diharuskan ramah dan senyum bila berhadapan dengan konsumen. Kemudian, baru-baru ini Hotel Santika Mataram menerapkan "Courtesy Call" atau bisa kita katakan cara untuk menyapa konsumennya melalui telepon, konsumen yang menerima courtesy call adalah mereka yang termasuk dalam returning guests. Bentuk desain antarmuka lain yang diterapkan Hotel Santika Mataram adalah sebuah website dengan alamat www.santika.com/santika-lombok. Website ini berisi segala informasi mengenai Hotel Santika Mataram, mulai dari fasilitas, promosi, harga, dan juga bisa melakukan booking online. Cara penyedia layanan lain untuk berinteraksi dengan konsumennya yang bisa menjadi sumber inovasi adalah dengan adanya "Guest Comments". Oleh karena itu, mayoritas penciptaan inovasi baru di Hotel Santika Mataram lebih dibentuk dari harapan konsumen.

c. Service Development and Delivery

Hotel Santika Mataram menerapkan pelayanan cepat maksimal 3 menit untuk reservasi dan express check in dan express check out. Pelayanan cepat bukan saja dalam hal reservasi, namun juga diterapkan di restoran, pelayanan cepat ini disebut juga dengan kata lain pelayanan simpel yang tidak muluk-muluk. Kemudian, Hotel Santika Mataram memotivasi karyawannya dengan job desk target, akan ada apresiasi atau reward khusus dari hotel kepada karyawan yang dianggap sebagai best employee yang dinilai selama 3 bulan sekali. Karyawan di Hotel Santika Mataram juga dilatih agar multi fungsi atau bisa mengerjakan pekerjaan dan menyelesaikan masalah di luar bidangnya atau jabatannya. Cara ini membuka peluang karyawan untuk berinovasi dalam memberikan pelayanannya kepada konsumen, karena bisa saja karyawan di bagian lain melakukan pelayanan tertentu yang berbeda dan baru terkait ilmunya

d. Technological Option

Hotel Santika Mataram menggunakan beberapa teknologi terkini dalam menunjang pelayanannya terhadap konsumennya. Selain menggunakan website, email, dan Online Travel Agency (OTA), untuk mendukung inovasi, pelayanan reservasi cepat ini didukung oleh sistem software komputer yang dikembangkan khusus bernama Front Office System (FOS). Kemudian penggunaan sistem kunci yang bernama VINGcard yang merupakan kartu magnetik. Sistem kunci ini akan diinstal sesuai lama menginap, jam masuk dan secara otomatis akan mengunci kamar apabila jam keluar yang sudah ditentukan pukul 12.01 P.M.

Berikut tabel yang memperlihatkan aktivitas inovasi dalam Hotel Santika Mataram dalam memberikan jasa kepada para konsumennya, serta pihak-pihak yang berperan dalam terciptanya inovasi tersebut. 


\section{Jurnal Magister Manajemen Unram Vol. 9, No 3. September 2020 NATIONALLY ACCREDITED JOURNAL - DECREE NO. 21/E/KPT/2018}

Tabel 4.1. Jenis Inovasi Hotel Santika Mataram dan Aktor Yang Berperan

\begin{tabular}{|c|c|c|c|c|}
\hline \multirow{2}{*}{ Aktor-aktor yang berperan } & \multicolumn{4}{|c|}{ Dimension Of Service Innovation } \\
\hline & Service Concept & Customer Interface & Service Development \& Delivery & Technological Options \\
\hline $\begin{array}{l}\text { Sektor Publik (Disbudpar NTB, } \\
\text { Polsek Mataram, Kantor Walikota } \\
\text { Mataram), GIZ }\end{array}$ & $\begin{array}{l}\text { - Event music corner, jazz corner } \\
\text { dan blues night (Kantor Walikota } \\
\text { Mataram) } \\
\text { - Special service (Polsek Mataram) } \\
\text { - Peta Kota(Disbudpar NTB) }\end{array}$ & - Brosur dan majalah & $\begin{array}{l}\text { - Leadership training every year } \\
\text { (GIZ) }\end{array}$ & \\
\hline Masyarakat & $\begin{array}{l}\text { - Penambahan omamen saat hari- } \\
\text { hari besar }\end{array}$ & & & \\
\hline Konsumen & & - Guest comments & & \\
\hline Petani ubi & - Menu baru (tortilla) & & & \\
\hline $\begin{array}{l}\text { Hotel-hotel lain yang ada di } \\
\text { Lombok }\end{array}$ & - Special rate & & & \\
\hline $\begin{array}{l}\text { Mitra Bisnis (Bank BCA, Telkom, } \\
\text { Garuda Airlines, Event Organizer, } \\
\text { outlet ABIPearls, La Tulip } \\
\text { Kosmetik) }\end{array}$ & $\begin{array}{l}\text { - Kartu Member SIP (BCA) } \\
\text { - Special price weekend (Garuda } \\
\text { Airlines) } \\
\text { - Event music corner, jazz corner } \\
\text { dan blues night (yankees } \\
\text { Enterprises) }\end{array}$ & $\begin{array}{l}\text { - Outlet penjualan mutiara dan } \\
\text { oleh-oleh khas Lombok (outlet } \\
\text { ABIPearls) }\end{array}$ & $\begin{array}{l}\text { - Becurty class (La Tulip } \\
\text { Kosmetik) }\end{array}$ & $\begin{array}{l}\text { - Kartu Member SIP (BCA) } \\
\text { - Line Telepon IP PABX } \\
\text { (Telkom) } \\
\text { - Wifi (Telkom) }\end{array}$ \\
\hline Sektor Pendidikan & $\begin{array}{l}\text { - Stand penjualan kerajinan tangan } \\
\text { lokal }\end{array}$ & & & \\
\hline Organisasi internal hotel & $\begin{array}{l}\text { - Minimalis (desain, energi, dan } \\
\text { biaya) } \\
\text { - Indonesian home (menu restoran) } \\
\text { - Special service (returning guest } \\
\text { dan long staying guest) } \\
\text { - Special rate }\end{array}$ & $\begin{array}{l}\text { - Hospitality from the heart } \\
\text { - Courtesy call } \\
\text { - Email blast } \\
\text { - Website resmi Santika }\end{array}$ & $\begin{array}{l}\text { - Express reservation, check in } \\
\text { \& check out } \\
\text { - Departure box } \\
\text { - Jobdesk target } \\
\text { - Multifungtion employee } \\
\text { - Internal training } \\
\text { - English class }\end{array}$ & $\begin{array}{l}\text { - Front office system (FOS) } \\
\text { - VINGcard }\end{array}$ \\
\hline
\end{tabular}

Nanggong (2013), menyatakan proses inovasi jasa tidak berasal dari internal perusahaan saja, tetapi juga berasal dari luar perusahaan, proses inovasi berbasis relasional. Hasil kerjasama dengan beberapa pihak, Hotel Santika Mataram mendapat pengetahuan yang kemudian dikonversi menjadi inovasi pada perusahaan. Dalam melayani konsumennya, proses service innovation yang dilakukan Hotel Santika Mataram sesuai dengan kerangka kerja yang digunakan dalam penelitian ini. Dalam kerangka kerja, dimensi Technological Options menjadi titik tengah bagi dimensi lainnya atau bisa dikatakan pemilihan penggunaan teknologi tertentu sebagai fasilitator penciptaan inovasi pada dimensi lainnya

\section{KESIMPULAN \& SARAN}

\subsection{Kesimpulan}

Berdasarkan hasil penelitian, akhirnya peneliti berhasil merumuskan kesimpulan sebagai berikut :

a. Peneliti mengidentifikasi inovasi yang menonjol berdasarkan kerangka kerja dalam penelitian ini pada keempat dimensi service innovation oleh Hotel Santika Mataram.

- Technological Options: Yang paling menonjol adalah penggunaan teknologi software FOS (Front Office System) yang hanya digunakan oleh anggota dalam organisasi Hotel Santika seluruh Indonesia.

- Customer Interface: Inovasi berkelanjutan lain adalah dengan terus memperbaharui menu makanan khususnya makanan lokal berkat harapan dari konsumen melalui Guest Comment.

- Service Concept: Hasil kerjasama dengan pihak luar menginspirasi Hotel Santika Mataram dalam menerapkan diskon dan harga spesial pada saat tertentu dan juga menerapkan express check in/out dalam konsep jasanya. 


\section{Jurnal Magister Manajemen Unram Vol. 9, No 3. September 2020 NATIONALIY ACCREDITED JOURNAL - DECREE NO. 21/E/KPT/2018}

- Service Delivery and Development: Terakhir adalah Hotel Santika Mataram melatih karyawan untuk multifunction agar mampu memberikan pelayanan yang memuaskan kepada konsumen.

\subsection{Saran}

Berdasarkan hasil penelitian, terdapat beberapa saran antara lain:

a. Hotel Santika Mataram agar tetap melakukan service innovation karena berdasarkan rujukan teori, inovasi merupakan hal yang berkesinambungan.

b. Peran dari sektor pendidikan khususnya Universitas masih tergolong kecil dalam keterlibatannya untuk menciptakan service innovation dalam Hotel Santika Mataram, sehingga disarankan agar pelaku bisnis untuk memberikan ruang lebih terhadap Universitas untuk terlibat secara aktif dalam penciptaan inovasi-inovasi baru.

c. Hotel Santika Mataram agar lebih fokus lagi untuk bersama-sama meningkatkan kualitas SDM secara luas di Lombok dengan memberikan edukasi-edukasi terkini. Hal ini berdasarkan kesimpulan penelitian dan saran dari para informan yang menyatakan bahwa kendala terletak pada Sumber Daya Manusia (SDM) khususnya sektor pendidikan dan masyarakat.

\section{DAFTAR PUSTAKA}

Gellatly, G., \& Peters, V. (1999). Understanding the Innovation Process: Innovation in Dynamic Service Industries. 127.

Harmon, R. R. (2012). Redefining Market Opportunities through Technology-Oriented Service Innovation. Portland State University.

Hertog, P. d. (2010). Managing service innovation: firm-level dynamic capabilities and policy options. (PhD thesis), University of Amsterdam (UvA), Amsterdam.

Hussain, K., Konar, R., \& Ali, F. (2016). Measuring Service Innovation Performance through Team Culture and Knowledge Sharing Behaviour in Hotel Services: A PLS Approach. Elsevier, 224(Social and Behavioral Sciences).

Kotler, P., \&Keller, K. L. (2009). Manajemen Pemasaran (13 ed. Vol. 2). Jakarta: Penerbit Erlangga.

Leich, D. M., Gokduman, S., \& Baaken, T. (2010). Service Innovation. Retrieved from Germany : Fachhochschule Munster University.

Lemy, D. M. (2010). Identifikasi Indikator Inovasi Layanan Yang Memengaruhi Preferensi Pelanggan Dalam Memilih Hotel. HOSPITOUR, 1(1).

Manual, O. (2005). Guidelines For Collecting and Interpreting Innovation Data: OECD.

Maruli, R., \& Ali, M. M. (2013). Proses Inovasi Pada Klaster Kampoeng Batik Laweyan Kota Surakarta. Jurnal Teknik PWK, 2.

Moleong, L. J. (2011). Metode Penelitian Kualitatif. Bandung: PT Remaja Rosdakarya.

Nanggong, A. (2013). "Inovasi Jasa Sebagai Keunggulan Kompetitif (Papers)" (Publication no. 10.13140/RG.2.2.21904.51202). from researchgate.net

Rahayu, J. S., Syairudin, B., \& Pertiwi, S. G. (2015). Perancangan Strategi Untuk Meningkatkan Kinerja Inovasi Pada Klaster Industri Kreatif Batik Laweyan. Paper presented at the Nasional Manajemen Teknologi XXII, Surabaya.

Weng, M.-H., Ha, J.-L., Wang, Y.-C., \& Tsai, C.-L. (2012). A Study Of The Relationship Among Service Innovation, Customer Value And Customer Satisfaction: An Empirical Study Of The Hotel Industry In Taiwan. International Journal of Organizational Innovation, 4 (3).

jmm.unram.ac.id 
Jurnal Magister Manajemen Unram Vol. 9, No 3. September 2020 NATIONALIY ACCREDITED JOURNAL - DECREE NO. 21/E/KPT/2018

World wide web:

https://www.cia.gov/library/publications/the-world-factbook/fields/214.html 